University of Nebraska - Lincoln

DigitalCommons@University of Nebraska - Lincoln

$10-2013$

\title{
Repunctuated Feminism: Marketing Menstrual Suppression Through the Rhetoric of Choice
}

Carly S. Woods

University of Nebraska-Lincoln, cwoods3@unl.edu

Follow this and additional works at: https://digitalcommons.unl.edu/commstudiespapers

Woods, Carly S., "Repunctuated Feminism: Marketing Menstrual Suppression Through the Rhetoric of Choice" (2013). Papers in Communication Studies. 44.

https://digitalcommons.unl.edu/commstudiespapers/44

This Article is brought to you for free and open access by the Communication Studies, Department of at DigitalCommons@University of Nebraska - Lincoln. It has been accepted for inclusion in Papers in Communication Studies by an authorized administrator of DigitalCommons@University of Nebraska - Lincoln. 
Published in Women's Studies in Communication 36:3 (2013), pages 267-287;

doi: 10.1080/07491409.2013.829791

Copyright (@ 2013 The Organization for Research on Women and Communication.

Published by Taylor \& Francis. Used by permission.

Previous versions of this manuscript were presented at the National Communication

Association convention and in the University of Pittsburgh's Women's

Studies Program Brownbag Lecture Series.

Published online October 14, 2013.

\title{
Repunctuated Feminism: Marketing Menstrual Suppression Through the Rhetoric of Choice
}

\author{
Carly S. Woods \\ Department of Communication Studies and the Women's and Gender Studies Program, \\ University of Nebraska-Lincoln, Lincoln, Nebraska, USA
}

\begin{abstract}
This essay examines the rhetoric of choice as it is used by direct-to-consumer campaigns to persuade women to limit menstruation through the consumption of oral contraceptives. Using the tools of feminist rhetorical criticism, I trace how choice is rhetorically constructed to suggest that menstrual suppression is a path to individual empowerment while co-opting second and postsecond-wave rhetorics. Finally, I explore the meaning of these constructions of choice and suggest broader implications for ongoing feminist movements.
\end{abstract}

Keywords: biomedicine, choice, direct-to-consumer advertisements, feminism, menstruation, pharmaceuticals, rhetoric

Choice, or the illusion of choice, is central to contemporary feminism. Easily aligned with activism aimed at empowering women to make decisions about their own lives and bodies, choice is ubiquitous, rhetorically powerful, and highly portable. Beyond its long and storied history within debates about reproductive rights, choice has gradually emerged as a key term to characterize a whole host of gendered issues, from conception to work-life balance. ${ }^{1}$ As such, it presents a rhetorical paradox: It holds the promise of individual agency but can also be co-opted to promote controversial choices that reinforce sexist stereotypes. What are the implications of the rhetoric of choice for ongoing feminist movements? How has choice been deployed in fresh discursive terrains? This essay explores these questions in the context of menstrual suppression, a topic that has only recently emerged in public discourse.

Our starting point is simple: Should menstruation be a choice? Not long ago, the idea that it could be a choice would have seemed absurd. Menstruation was not a decision to be pondered; it was a reality to be dealt with. Yet twenty-first century advances have in- 
troduced pharmaceuticals that make this issue increasingly relevant. ${ }^{2}$ Oral contraceptives have been specifically developed and marketed to limit menstruation. When posited as a needless reminder of biological difference, the decision to suppress menstruation may seem like an uncontroversial personal choice. For example, in the advertising campaign for Seasonique, an oral contraceptive that limits menstruation to four times a year, Duramed Pharmaceuticals implicitly argues that menstruation is an unnecessary event with the slogan "Repunctuate your life with fewer periods." Here, the magic of modern biomedical technology presents a simple and yet potentially liberating option: Consume a pill and take control of your life.

But what does it really mean to repunctuate one's life? To punctuate has a double meaning - it can designate a periodic interruption (to punctuate a silence with sound; a punctuation mark interrupts or divides a sentence from another), or it can mean to accentuate (to emphasize or intensify). Seasonique's campaign plays on menstrual periods as punctuation and promises to correct for the way they interrupt women's lives. On the other hand, some scholars see menstruation as an important part of gendered identity. Beyond its physiological purposes, those who promote this perspective believe that menstruation can be significant to individuals and as a collective experience for women. Feminist political philosopher Iris Marion Young gives voice to the value of menstruation in both senses. Her essay "Menstrual Meditations" in On Female Body Experience does not deny that menstrual periods disrupt everyday routines but instead argues that disruptions can be valuable reminders to take time out: "Because the event returns monthly, it affords an experienced discontinuity that prompts one to look back and forward.... Because menstrual moments punctuate our lives, they easily orient our self-narrative" (12021; emphasis added). If embraced for its reflective possibilities, menstruation can allow for a productive indulgence in one's affective states.

In other work, Young offers a way to understand the relationship between menstruating individuals and collective gendered identity. Borrowing from Sartre, she conceives of gender as a series, or a "social collective whose members are unified passively by the objects their actions are oriented around and/or by the objectified results of the material effects of the actions of others" ("Gender as Seriality" in Intersecting Voices 23). This approach offers a middle ground between the problem of defining women on the basis of perceived commonalities, which risks essentialism, and the promise of practical political action that necessitates seeing women as a group in order to conceptualize oppression on a systematic level (Young, Intersecting Voices 13). Using menstruation as a primary example, Young explains that it is not the biological event that creates a series but "rather, the social rules of menstruation, along with the material objects associated with menstrual practices, [which] constitute the activity within which the women live as serialized" (Intersecting Voices 28). In other words, menstruation creates a material reality that has the potential to connect women, and it may be important to the ways that some women imagine themselves as gendered beings. Although not all women menstruate; women who menstruate do not do so all of the time; and the experience of menstruation varies widely between individuals, ${ }^{3}$ the assumption of menstrual pain is often cited to support sexist attitudes that limit all women:

Women who experience debilitating mental or physical pain at menstruation (despite the easy availability of The Pill and other such remedies) are made the prototype for all; and in the face of statistics to the contrary; 
women are still considered unreliable workers and unstable human beings at that time of the month. Thus, menstruation is a factor in the control of women by men not only in ancient and primitive societies, where knowledge of physiology is rudimentary at best, but also in our post-industrial world. (Delaney et al. 3-4)

As a physical and social reality, menstruation is a source of serial connection in Young's sense. Based on this perspective, menstruation is significant not because every woman celebrates it but because it can serve as the basis for a shared political subjectivity. If menstruation is framed not as a condition that passively defines women but as an active choice that individuals may opt out of at will, the potential of this connection is tempered.

These competing perspectives about the value of menstruation do not exist in a vacuum. They are representative of broader anxieties concerning gender, choice, and biomedicine. Although it has been called "strategic for women's liberation," biomedicine is also "strategic to women's oppression" as a source of sexist ideology and discrimination (Ehrenreich and English 5). Feminist scholarship has been pivotal in identifying moments of medicalization, when social issues are turned into medical problems and bodily differences are cast as diseases or illnesses that one can choose to treat (Lorber and Moore 6, 65). Recent technological advancements have created new opportunities to medicalize women's bodies, and new occasions to exercise choice, especially in reproductive matters such as menstruation, conception, and childbirth. When medical professionals operate under the assumption that the male body is the norm, women's health has the potential to become pathologized, overmedicalized, and subject to unnecessary technological intervention. As a result, there have been calls for greater patient empowerment, informed consent, and medical knowledge rooted in personal experience (Willard; Hayden). Yet shifts toward patient-directed health care are not without vulnerabilities. Any movement toward greater patient empowerment in health care has to contend with a complex web of industry-driven discourses. A host of drugs and procedures are now marketed to go beyond what is medically necessary; we have the ability to use "enhancement technologies" to make ourselves "better than well" (Elliott). We can google our way to a WebMD diagnosis and are encouraged to script conversations with health care providers when we see ourselves in pharmaceutical advertisements. Pharmaceuticals increasingly offer women the "choice" to solve whatever ails their bodies, even while the nature and gendered meanings of those ailments are in flux (Zita 68).

This essay draws attention to the ways oral contraceptives are now being marketed as medical technologies that materially and discursively transform menstruation into a personal choice, thus circumventing discussions about its cultural value. ${ }^{5}$ I consider the direct-to-consumer (DTC) advertising campaigns of four oral contraceptives approved by the U.S. Food and Drug Administration (FDA) to limit menstruation: Bayer Healthcare Pharmaceutical's Yaz, Warner Chilcott's Loestrin, Duramed Pharmaceutical's Seasonale, and its second-generation brand name, Seasonique. ${ }^{6}$ DTC advertisements are public texts that showcase how expert discourses "draw on the shared pools of language and imagery and argumentative strategy that are available to members of the more general culture" (Lyne and Miller 170). ${ }^{7}$ Such advertisements seek to inform and shape consumer attitudes about drugs, and are highly interactive, dynamic texts that are regularly revised in response to consumer demand and FDA warnings. ${ }^{8}$ To analyze the rhetorical construction 
of menstruation as a choice, I examined the visual and textual components of each pharmaceutical's Web-based campaigns from 2006 to 2010, a time period when DTC advertising of these products was at its height. ${ }^{9}$ Early iterations of the campaigns provide particularly rich artifacts for analysis, as they ventured into the relatively uncharted territory of crafting arguments about the ability to suppress menstruation.

My analysis is informed by rhetorical studies of medicine and feminist rhetorical criticism. Rhetorical analysis plays an important role in exploring whether it is possible or desirable to hold on to bodily difference amidst rapid biomedical development, allowing communication scholars to "pos[e] questions that are prior to the questions typically posed by health researchers" (Segal, "Rhetoric of Health and Medicine" 228). In decoding the process of negotiation and translation amongst culture, biomedicine, and industry, such analysis can highlight disparate lines of argument, identify the stakes, and mediate the conflation of medicine and values in biomedical controversies (Lyne 8). ${ }^{10}$ Feminist rhetorical criticism is particularly well suited to study choice within the campaigns because allowing "people to understand that they have the capacity to claim agency and act in the world as they choose" is its raison d'être (Foss 157). As Sonja K. Foss explains, "Gender is a culture's conception of the qualities considered desirable for women and men, a construction created and maintained through various forms of rhetoric. In feminist criticism, then, the focus is on the rhetorical process by which these qualities come to seem natural and ways in which that naturalness can be called into question" (157).

Feminist rhetorical criticism enables us to see how the process can be inverted, as the DTC advertisements present menstruation as an undesirable condition for women that is unnecessary, unnatural, and detrimental to one's true identity. I trace how each campaign encourages women to make the choice to repunctuate (accentuate) their lives with menstrual suppression, finding that such discourses (a) appeal to agency and personal choice using a post-second-wave rhetoric of feminine empowerment or (b) co-opt second-wave feminist rhetorics by conflating the choice to alleviate unwanted pregnancy provided by access to oral contraceptives with the choice to alleviate menstrual symptoms today. Absent from these appeals, of course, is a consideration of how menstruation could be seen positively. In this case, feminism itself may be repunctuated (interrupted) as "choice" facilitates a sense of agency over one's own body but risks simultaneously reinscribing patriarchal beliefs about menstruation.

\section{To Menstruate or Not to Menstruate? The Choice Is Yours}

In their book Contemplating Maternity in an Era of Choice, Sara Hayden and D. Lynn O'Brien Hallstein underline the centrality of choice in public discourse: "Choice is part of the contemporary lexicon, a term that, to greater or lesser extent, shapes and is shaped by women's and men's (reproductive) lives" (xxviii; emphasis in original). Although it is often associated with feminism, choice remains a highly disputed term. Some hail the freedom to exercise choice - any choice - as the defining factor of pluralistic post-secondwave feminism (Baumgardner and Richards 450; Snyder-Hall). Others critique the ways that choice has been depoliticized to support practices that reentrench traditional gender roles, counter second-wave feminist gains, and sever ties to collective activism (FixmerOraiz 42-43; Ferguson; McCarver; O’Brien Hallstein). A number of studies have made 
clear that the rhetoric of choice has the potential to both empower and discipline in a number of reproductive matters such as contraception, conception, childbirth, and worklife balance (see Hayden and O'Brien Hallstein, esp. Fixmer-Oraiz). Interestingly, rhetorics of choice and empowerment have also been used to mediate between acceptable and unacceptable bodily alteration practices, including plastic surgery and female genital "cosmetic surgery" (Jordan; Braun). Of course, the ability to access and exercise choice is always influenced by a number of factors, including "relationships with others, mental and physical health, race, sexual orientation, and economic status, public and workplace policies, developments in reproductive technology, and the social norms and messages communicated to women about the appropriateness of becoming mothers (or not)" (Hayden and $\mathrm{O}^{\prime}$ Brien Hallstein xvii). ${ }^{11}$

Given the pervasiveness of choice in contemporary culture, it is unsurprising that the DTC campaigns analyzed here attempt to make menstruation itself a choice. But this raises the question: What exactly does choice mean in the context of menstruation, and what is at stake for women's lives? Philosophically, feminine corporeality has been conceptualized as an uncontrollable flow in Western culture, a permeable boundary that leaks and bleeds (Grosz 203-204). The idea that the literal and figurative flow of women's bodies needs to be contained is nothing new. Historically, menstruation has not functioned within the realm of choice - it was a shameful process that girls and women were taught to conceal. As Roseann Mandziuk illustrates, this message surrounding menstruation can be traced to sanitary napkin advertising in the early twentieth century. Biomedical and consumerist discourses about menstruation have long existed in a symbiotic relationship, where "medicine contributes the impression that menstruation renders women offensive and incomplete; advertising discourses, in turn, offer products to compensate for this inadequacy, women's perpetual 'problem'" (Mandziuk 42). Before the advent of pharmaceuticals marketed to suppress menstruation, the rhetoric of choice was limited to choice about what kind of personal hygiene product (sanitary napkins, tampons, etc.) should be used to best conceal it. In the analysis that follows, I trace how such oral contraceptive campaigns introduce a whole new era of menstrual concealment that urges individuals to make the choice to empower themselves by addressing menstrual symptoms, enhancing their lifestyles by shortening their monthly periods, or reclaiming lost time by reducing the number of periods they experience each year.

\section{Yaz: "We've Got the Right to Choose"}

Bayer Healthcare Pharmaceuticals' oral contraceptive, Yaz, is the first birth control pill approved by the FDA to address premenstrual dysphoric disorder (PMDD), a condition of heightened emotional and physical stress occurring up to ten days before menstruation. It is differentiated from but sometimes described as a severe form of premenstrual syndrome (PMS). ${ }^{12}$ Bayer enlisted the help of the global communications agency MediaEdge: Cia (MEC) to prime consumers about PMDD before the official release of the pharmaceutical. With the stated goal of "activating girl power," MEC created a multimedia campaign to "engag[e] with young women about confidential health choices through music and online content." Girl power assumes a level of gender equality not present in second-wave feminist efforts, urging young women to tap into their (already) empowered feminine selves (Hains 98). Not to be confused with the "grrrl power" promoted by feminist punk bands, "girl power" was propagated through 1990s' popular culture (think 
Spice Girls, not Bikini Kill). In fact, by 2002, the idea of girl power was so mainstream that it was added to the Oxford English Dictionary, which describes it as "a self-reliant attitude among girls and young women manifested in ambition, assertiveness, and individualism" (BBC News). Entangled in commercialization and popular culture, some argue that girl power is a characteristic feature of postfeminism. Postfeminism, as defined by feminist media scholar Angela McRobbie, is an "active process" that undoes second-wave feminist accomplishments even while "appearing to be engaging in a well-informed and even well-intended response to feminism" (255). ${ }^{13}$ Bayer's DTC campaigns about PMDD and Yaz used appeals to empowerment to position menstrual symptoms as a problem that strong women choose to fight back against.

MEC notes that feminine empowerment was a cornerstone of the campaign, which operated under the driving insight that "women want to be in control of their bodies ... yet they believe that severe PMS is normal and silently accept debilitating symptoms" (MediaEdge: Cia). Their solution was to create a three-pronged "unbranded education campaign."14 First, they hired an Australian band, The Veronicas, to record Twisted Sister's 1984 top-40 song, "We're Not Gonna Take It." The band, which has been called postfeminist and even post-postfeminist, was the perfect choice for the campaign: The young, hip, Origliasso sisters projected an alternative brand of girl power but were still willing to make guest appearances at the Miss USA pageant (Haruch). The former glam-rock hit took on new meaning when sung by The Veronicas. A stylistic and sonorous update to second-wave feminist anthems such as "I Am Woman, Hear Me Roar," "We're Not Gonna Take It" was transformed. No longer was the song intended to target patriarchy; instead, it addressed the bloating, headaches, and depression that sometimes accompany menstruation. Lyrics such as "we've got the right to choose" make menstrual symptoms a choice that the consumer can opt out of by opting in to use Yaz. If menstruation is a choice, and women have the right to choose, why not exercise that right? Why just "take it"?

The second element of the MEC's unbranded campaign was a Web site, wngti.com, intended to drum up interest in PMDD before the unveiling of the Yaz campaign. ${ }^{15}$ Outlined in bright pink and decorated with hearts, the Web site allowed consumers to get a behind-the-scenes peek at The Veronicas and make a connection between the lyrics and their feelings about menstruation: The band suggests that their fans and "women everywhere ... should take action to live the best life they can, emotionally and physically" (wngti.com). Visitors obtained a free download of the song by entering the code "understandpmdd" and their e-mail into a form on the Website, and could enter a video contest with their own a capella version of the song. Once users requested to download the song, they were prompted to visit another Web site, UnderstandPMDD.com. MEC reports that the song was downloaded more than 350,000 times and that 42,000 people visited the Web site over a three-month period (MediaEdge: Cia).

Of those 42,000 users, $70 \%$ continued on to the third and final component of MEC's campaign: the companion Website, UnderstandPMDD.com (MediaEdge: Cia). The Web site provided consumers with information needed to self-diagnose PMDD. Women were told that they should understand their monthly symptoms and were asked to record their experiences in a "body diary" to help evaluate the severity of their PMDD symptoms. Here, tracking one's symptoms is framed not as bodily regulation but as a record of what one can choose to overcome. Highlighting the loss of time that PMDD sufferers experience, visitors to the Web site were asked: "Do you feel like half of the month isn't yours?" 
When framed as a condition that robs them of their right to live full lives, the choice to suppress menstrual symptoms seems like an easy one to make.

These messages are supported by the images on the Understand PMDD site. PMDD can be physically and emotionally debilitating, and pharmaceutical intervention allows women to fight back. Each image invokes the idea that women need to take control, mobilizing various self-defense techniques against the PMDD symptoms that are waiting to attack. In one image, a woman in workout gear stands in ready position, her hands clad with boxing gloves, and stares straight into the camera, her teeth gritted, and her mouth in a half-smile. Across her waist is the now familiar lyric: "We're not gonna to take it." Another image shows the same woman doing a karate kick, shattering a banner labeled "mood swings." The next page shows a woman in a dress hitting "irritability" with a lamp. The "Talk to Your Healthcare Professional" and "FAQ" pages include images of women squeezing the banner that says "food cravings," and pushing back against "fatigue" (UnderstandPMDD.com). That the campaign decided to focus on self-defense is telling as we attempt to decode the relationship between the pharmaceuticals and feminist rhetoric. Self-defense has long been associated with feminist movements in the United States, in that it provides a mechanism to fight back against gender-based violence. Self-defense classes for women were established and popularized during the second-wave women's movement. Yet as Whitney Walker's contribution to the popular third-wave volume Listen Up! Voices from the Next Feminist Generation makes clear, empowerment through self-defense continues to be a potent feminist strategy for contemporary women. Walker found her own "feminist awakening" through self-defense courses after she was made to feel vulnerable by a male flasher and came to realize that "self-defense is becoming as important to my generation of the women's movement as it was to my mother's" (128). Whereas self-defense was made meaningful in the past because it allowed women to resist forced subordination to violent perpetrators, the UnderstandPMDD.com Web site urges women to resist subordination to their own bodies. PMDD symptoms are figured as the attackers, and Yaz becomes a weapon of individual empowerment, functionally co-opting feminist rhetorics of self-defense to combat violence against women.

After cultivating an audience with MEC's efforts, Bayer Healthcare Pharmaceuticals followed up with the official launch of the Yaz Web site and television advertisements. The Web site promised that women taking Yaz could go "beyond birth control." Consumers could not only prevent unwanted pregnancies but also have shorter, lighter periods, and fight back against menstrual pain such as "anger, irritability, depressed moods, feeling anxious, bloating, change in appetite, headaches, and muscle aches ... and acne" (Yaz-us.com). Two television advertisements, "Not Gonna Take It" and "Balloons," were launched in 2008. Both featured The Veronicas' songs as background music ("Balloons" also featured the song "Goodbye to You"). The "Not Gonna Take It" spot adapted the images of women "fighting" PMDD symptoms from the UnderstandPMDD.com Web site for television audiences, while the "Balloons" ad showed women "letting go" of PMDD symptoms labeled on balloons, sending their menstrual pain and suffering away.

In 2008, the FDA issued Bayer an official warning for the television advertisements. The campaign was charged with misleading consumers "from a public health perspective, because they encourage use of YAZ in circumstances other than those in which the drug has been approved, over-promise of the benefits and minimize the risks associated with YAZ" (Abrams 1). The FDA letter to Bayer's president and chief executive officer Re- 
inhard Franzen detailed a number of violations, including that the advertisements used the acronym PMDD but never spelled out the proper name of the condition, increasing the likelihood that consumers would conflate it with PMS; that it indicated Yaz could be used to treat acne of any severity level; that in suggesting consumers could "say goodbye" to their symptoms completely by letting go of balloons or kickboxing away the symptoms, they overstated Yaz's effectiveness in treating PMDD; and finally, that the risks of taking Yaz were minimized due to "distracting visuals, numerous scene changes, and other competing modalities such as background music" (Abrams 6). Bayer was then told to air corrective advertisements to set the record straight.

By incorporating a "postfeminist" band to play background music, appealing to a "girl power" sensibility, and encouraging women to (literally) fight back against PMDD, Bayer positioned Yaz as a means of individual empowerment. Instead of collectively organizing to address social ills, women are encouraged to see menstrual suppression as a right that they can and should freely choose to exercise to gain control over their lives. As the next section reveals, another campaign strategy continued this message of individual empowerment but also suggested that menstrual suppression is not only a right-it is a proactive lifestyle choice.

\section{Loestrin: Choosing Shorter Periods}

Warner Chilcott's Loestrin24fe is an oral contraceptive pill that shortens the length of menstrual periods from an average of five to seven days to three days. Instead of framing (pre)menstrual symptoms as obstacles to fight against, a narrative approach articulated menstrual suppression as a choice to enhance one's lifestyle. The initial campaign included Web site and television advertisements that placed a particular emphasis on the shorter length of periods offered by the drug. For example, visitors to the Web site were greeted with a banner that read "The pill with a short period." As readers scrolled down to read answers to such questions as "Are shorter periods ok?" and "How does Loestrin24fe shorten my period?," they were told to click on a link labeled "The short way back up" to return to the top of the page (Loestrin24.com). ${ }^{16}$

Perhaps the most provocative element of the Loestrin Web site was the elaborate story told about Cammie, the character on the drug's television ads. The television commercial, which was also available on the Web site, plays out a thirty-second narrative about a White, hip, cosmopolitan woman seen on a laptop, typing "how to say so long to a period that's too long" into a search engine. The commercial does not get into great detail, but we see different shots of Cammie enjoying life in her apartment, hanging out with her dog and then with a man. However, visitors to the Web site were given more information about how to interpret the television ad: They could click on a link to "meet" Cammie. This link took potential consumers to the very detailed world of Cammie, where they could learn about Cammie's life, friends, favorite bands, hobbies, and interests. Consider this excerpt:

Cammie is an aspiring textile designer in her mid-twenties. She works out of a shared studio in the same building where she rents her loft apartment in Alphabet City, a funky downtown neighborhood in NYC.... Cammie's taste in just about everything is eclectic. Her clothes. The way she decorates her apartment. Her friends. Most definitely her taste in music. Even the guys she dates. 
She's got this amazing instinct for putting together the most interesting, and more often than not offbeat, people and things. Speaking of guys, Cammie's just met Ryan, a production assistant and part-time lead singer in a local alternative rock band. He's definitely cute and a lot of fun to be with, but Cammie just wants to be friends. You see, she just broke up with her college boyfriend, Kevin, and she's still too tender from it to want to jump right back into a serious relationship. (Loestrin24.com, "Cammie's Story")

Cammie is positioned as an atomized individual whom we see in relation to her work, romantic relationships, and her pet. The Web site uses an exhaustive narrative appeal designed to make readers feel as if Cammie is the type of person that they can identify with. Loestrin's manufacturers make their target demographic very evident: White, young, single, heterosexual women interested in music, fashion, and upwardlymobile urban living.

The lifestyle norms that characterize this demographic demand a calendar unpunctuated by the nuisance of lengthy menstruation. Cammie's story explains how taking Loestrin can guarantee a vibrant social life by highlighting the significance of the number three and the word "short" in her life. We learn that Cammie's favorite number is three: she was born on $3 / 3$, she is the youngest of three sisters, and the new guy she is dating has three threes in his phone number. Perhaps most incredibly, even her dog's story corresponds to the shorter periods that Cammie will soon experience on Loestrin. That's right: Cammie's dog is named Shorty. Shorty is described in great detail, and there are even links to the Basset Hound Club of America and the American Kennel Club embedded in "Shorty's story" (Loestrin24.com, "Cammie's Story"). The campaign goes to bizarre lengths to hammer home the message: "So, you can imagine how lucky Cammie felt when she discovered that Loestrin 24 Fe is a low estrogen birth control pill with periods that last on average less than 3 days."

Loestrin's narrative approach may seem over the top, but it fits perfectly with the strategy of creating an identity for the consumer rooted in the individual choice to limit menstruation. Narratives often play fundamental role in constitutive rhetoric, opening "diagetic spaces, story spaces, which are meaningful because they produce identification with a point of view" (Charland 617-18; emphasis in original). Narrative appeal in advertising is particularly important in a world dominated by overpersonalization. In positioning Cammie as a "normal" young woman who does not want to be burdened by the usual length of menstrual periods, Loestrin's DTC advertisements create diagetic spaces that facilitate identification between the consumer and a fictional character. The "story spaces" created by Cammie's online biography mimic online social networking Web sites, where users can go to find out specific details of their friends' lives and oversharing is a norm. Consumers can imagine her as a real person, a model of what they could be if they also made the choice to use Loestrin.

There is an implicit assumption that women should have sexual freedom in the campaign; Cammie clearly isn't ready to settle down, and the Pill assures that she doesn't have to. Yet Loestrin's ability to prevent unwanted pregnancies is secondary to its claim to shorten menstrual periods. Like Yaz, the campaign draws from post-second-wave feminist rhetorics by focusing on individual choice and consumer culture. As Helene Shugart, Catherine Eggley Waggoner, and D. Lynn O'Brien Hallstein explain in their investigation of appropriations of third-wave feminism, "Being empowered in the third-wave sense is 
about feeling good about oneself and having the power to make choices, regardless of what those choices are" (195). The Loestrin DTC campaign co-opts this sense of choice, moving beyond the third wave and into a postfeminist rhetoric of choice that divorces individuals from a greater sense of social justice or feminist history. It stresses that individuals can choose to have a lifestyle like Cammie's through pharmaceutical intervention. Of course, the campaign is not about providing all women with choices. Rather, the focus on individual lifestyle choices reaffirms sanitized, White, middle-class social and career norms and ignores the very real obstacles encountered by those who do not have access to this type of lifestyle (Zita 68). The DTC campaigns for Duramed Pharmaceuticals similarly promote menstrual suppression as a way to enhance individual lives, offering women the option to empower themselves by reclaiming time lost to menstruation.

\section{Seasonale/Seasonique: Choosing Fewer Periods}

While Yaz promises to combat menstrual symptoms and Loestrin promises to limit the number of days per month a woman spends menstruating, Seasonale and Seasonique boast the ability to limit the number of periods experienced each year. As the first menstrual suppression drug to be approved by the FDA, Seasonale received much media attention (Fried; Payne). ${ }^{17}$ This oral contraceptive reduces the occurrence of menstruation from thirteen times a year on a traditional birth control pill to four times a year (hence the reference to the seasons in both drug names). ${ }^{18}$ Drawing on the idea that menstruation impedes a "normal" life, these campaigns employed some of the themes of empowerment and lifestyle enhancement evident in the marketing strategies discussed so far. Unique to Seasonale and Seasonique, though, is a focus on ensuring that schedules and life trajectories are not disrupted by menstruation.

With its focus on fewer periods, the Seasonale campaign focused on the theme of time loss as an argumentative topos. Clearly attentive to the concerns that women may have about the dangers of menstrual suppression, two slogans, "Seasonale: the daily birth control pill that's the same but different" and "Fewer periods, more possibilities," stressed that this choice would be an easy change with significant benefits. Visitors to the Seasonale Web site were encouraged to use an interactive personal planner where they could "plan events like vacations, business travel, romantic encounters, and family reunions" with the luxury afforded by more time between menstrual periods (Seasonale.com). By identifying the benefits that women might garner from fewer periods, the campaign appealed to other activities that consumers might see as central to their identity. They urged women to define themselves by romantic encounters and vacations, rather than by menstruation: their schedules don't need to be flexible as long as their bodies are open to pharmaceutical intervention. There was also an attempt to win over skeptics by asking them to imagine their lives undisrupted: "Not yet a SEASONALE® user? You can still use the Personal Planner to plan activities and see when your inactive Pill dates would happen if you were taking SEASONALE®" (Seasonale.com, "Seasonale Personal Planner").

Women seeking online information about menstrual suppression could also visit a companion Web site FewerPeriods.com, run by Duramed Pharmaceuticals. At this site, readers were greeted with the images of three young, confident-looking women and an 
older - and presumably wiser - woman with a lab coat and a stethoscope around her neck. The Web site informed visitors that they had come to the right place to uncover the "truth about fewer periods," with answers to such questions as "Why are fewer periods possible?"; "Is it safe?"; "Will it affect fertility?"; and "What do the experts say?" (FewerPeriods.com). Women were encouraged to talk to their health care professionals about having fewer periods by creating a free, personalized discussion guide to take to their office visit. Essentially, a pharmaceutical company was scripting the conversation that patients might have with their doctors so that the doctor would write a prescription for their product.

In May 2007, an advertisement for Duramed's Fewer Periods Web site ran in Shape magazine (Duramed Pharmaceuticals). The four-page ad begins with the image of a young blonde woman on the beach, throwing her hands up in glee and trying to twirl two Hula-Hoops around her hips. Why does this woman have two Hula-Hoops? The two Hula-Hoops could easily represent the well-known desire to "have it all": a rewarding balance between work and home activities. However, in this formulation, it more likely represents the balance between everyday life and the management of her menstruation. The accompanying text asks readers, "Entertaining the possibility of fewer periods? It may be possible if you are on hormonal birth control. Most women agree that life would be nicer if they could have fewer periods." In other words, use our product and you will be able to manage your two Hula-Hoops with ease.

The ad then goes on to give a brief history of the Pill under the heading Periods in the 21st Century. As the reader turns the page, they see a medical advice column, "Ask Dr. Sulak," in which the doctor answers questions about health concerns and convenience factors involved in making the decision to have fewer periods. "Cathy," for instance, says she does not want her period to happen while she is on her honeymoon but is afraid that she won't be able to get pregnant in the future if she suppresses it. Dr. Sulak puts her mind to rest - getting fewer periods on birth control will not affect her ability to get pregnant once she ceases to take the medication. And if "Cathy" wasn't convinced by Dr. Sulak's advice alone, the ad includes an image of a young, blonde, White mother smiling and holding up a young girl to confirm postsuppression fertility, visually assuring worried women that a future of happy motherhood would not be altered.

The final page is perhaps the most revealing of the normative assumptions behind the ad. On the left-hand side of the page, there is a sidebar called "Turning Points in Contraception" that contains bullet points showing "new phases" in a woman's life: starting a new relationship, getting married, and having a baby. Each of the three phases is accompanied by a morsel of advice: a woman in a new relationship will want to reevaluate her birth control; an engaged woman will be wary about her period "interrupting" her honeymoon; and a new mother must realize that her "time is not [her] own, and [she] will need to evaluate whether refilling a prescription every month and dealing with monthly cramps [will interfere] with [her] new responsibilities." In collapsing women's lives down to these three phases, the advertisement defines women by their roles as girlfriends, wives, and mothers; never mind if a woman is not in a relationship with a man or does not want to, or cannot, have children. The accompanying image on this ad page is a light-skinned African American woman, standing in a field with her head tilted upward, a smile on her face (Duramed Pharmaceuticals). The ads suggest that consuming Seasonale can enable individual women to better fulfill traditional gender roles. 
In 2009, the campaign evolved to promote the next generation version of the drug, Seasonique. The Seasonique Web site, Seasonique.com, maintained much of the content previously available on the safety and convenience of limiting menstruation to four times a year. It also maintained a focus on reclaiming loss time: the new campaign adopted a new slogan, "Repunctuate your life with fewer periods." Recalling the double meaning of punctuate discussed earlier - either as a periodic interruption or an intensification - we can see that the strategy is to convince women that menstruation is an unwanted periodic disruption but that pharmaceutical intervention can accentuate their otherwise wonderful lives. The Seasonique Web site was unique in that it explicitly used historical arguments to differentiate contemporary women from their predecessors. Constitutive rhetoric constructs individuals through three distinct modes of identification: collective identity, as subjects in history, and as subjects who act in sync with their historical identities (Charland 617). Like the girl power invoked in the Yaz campaign, it references feminist history to demonstrate how women have moved beyond second-wave feminist concerns with coalitional solidarity. Consumers need not experience monthly menstruation for the reflective period or as a point of serial connection with other women. Yet the Seasonique campaign positions the unpunctuated lifestyles enabled by menstrual suppression as the next step in a feminist progress narrative. Contemporary women are urged to take Seasonique so that their lives will be minimally disrupted, without the pain or nuisance of menstruation that previous generations of women had no choice but to endure. The campaign constructs individuals as subjects in history who can choose to act in sync with and distinguish themselves from their feminist foremothers.

By clicking on "The Real Story of the Pill," visitors to the Web site read a historical narrative aimed at persuading women that there is no medical need for monthly periods. But it was not a lecture: A history of oral contraceptives was told with a snarky, sarcastic flair made popular by commodity-driven, post-second-wave feminist publications like Bust magazine. The history included a timeline that stretched back to Genesis, making historical pit stops along the way. In 384 BCE, for example, we learned that "Old Greek men" were doing "Old Greek things" when Aristotle, "one of the smartest men in the history of history, decides it's a good idea to use natural chemicals ... as a spermicide." Fastforwarding to first-wave feminism in the United States, the timeline touched down on milestones in the development of birth control such as in 1873, when "Congress' questionable taste in porn becomes apparent when they classify birth control as obscene material" and Margaret Sanger's 1912 dream of a "magic pill." Biomedical advances such as the discovery of progesterone were charted with built-in jabs at menstrual stereotypes: "1928: Progesterone, one of the primary hormones that causes the menstrual cycle, is discovered. Science rejoices. Then cries a little bit. Then rejoices again. Followed by more laughter and fits of crying before finally deciding to take it all out on her boyfriend" (Seasonique.com, "The Real Story of the Pill").

The pivotal date on the timeline is 1954, when Gregory Pincus and John Rock invent the Pill. The historical narrative promoted by Duramed here is that to appease Rock's church, they built a "fake period" into the oral contraceptive regimen. Second-wave feminist accomplishments such as the integration of more women into the workplace, the popularization of the Pill, and changing gender roles in the family temporally coincide on the continuum with FDA approval of oral contraceptives. "Today" was marked on the timeline with an acknowledgment that the recent FDA approval of extended pill regimens was right in step with other accomplishments, conflating the sexual liberation and 
alleviation of unwanted pregnancy provided by the Pill in the 1960s with personal liberation and alleviation of unwanted menstruation today because women can "repunctuate their lives with four periods a year."

The "real story of the pill" provided consumers within a grand narrative of overbearing men versus smart, organized women fighting for additional rights such as the ability to make their own decisions about oral contraceptives. It offered a way for contemporary women to acknowledge themselves as subjects in feminist history who, to act in accordance with that history, need not collectively organize against patriarchal views towards menstruation. If women in the 1960s organized for access to the Pill, wouldn't they also embrace advancements in medical technology that offer individuals the choice to suppress menstruation today? Seasonique's marketing strategy borrowed from reverence for the accomplishments of second-wave feminist activism but promoted a pharmaceutical that would erase monthly menstruation as a link between women. It took the message of individual empowerment through the reclamation of one's time introduced in the Seasonale campaign and embedded it within a broader feminist historical frame.

\section{Punctuated Lives, Possible Futures: Feminisms and the Rhetoric of Choice}

Although they have different points of emphasis, the campaigns for Yaz, Loestrin, Seasonale, and Seasonique all draw attention to women's empowerment and agency over their own bodies and lives. For women who experience debilitating pain during menstruation, or those who do not intend to become pregnant, this pharmaceutical intervention may be quite liberating (Edelman). Transmen may find menstrual suppression useful as a part of hormonal therapy. Some women in the military have expressed an interest in menstrual suppression during deployment (Trego; Powell-Dunford et al.). In each of these cases, menstruation and its gendered baggage may feel unnecessarily restrictive. To be sure, DTC advertisements are first and foremost concerned with selling a product, and they are operating within a long tradition of marketing discourses borrowed from social movement rhetorics. Yet insofar as choice and agency are fundamental to post-second-wave feminisms, the rhetorical construction of choice surrounding menstrual suppression should be applauded for articulating and amplifying a choice where one did not seem to exist before. These discourses have the potential to repunctuate (productively disrupt or rupture) a single feminist narrative that assumes a monolithic relationship between individuals and menstruation.

However, this study also highlights some troubling moves within the DTC campaigns. First, the campaigns studied here posit menstrual suppression as a choice that should be exercised by all women or as a choice befitting a particular lifestyle. The Yaz and Seasonique slogans employ a strategic ambiguity in which anyone becomes a candidate for menstrual suppression. Who exactly, is the "we" in "We're not gonna take it"? Whose life should be "repunctuated" "with fewer periods"? The Loestrin and Seasonale campaigns are narrow in their respective representations of mostly young, White, heterosexual, middle-class women and those who expect their life courses to include heterosexual dating, marriage, and childbirth. This is problematic in that the campaigns seem to either massproduce a need for menstrual suppression where it may not exist or reproduce limited gendered scripts. My concern is that those who may find the choice to suppress menstru- 
ation most empowering - those with debilitating menstrual pain, those who do not intend to become pregnant, trans men, and women in the military, among others - do not seem to be the target audiences for these advertisements.

Second, these discourses assume that any debate about the value of menstruation has already been settled. In constructing menstrual suppression as a route to individual feminine empowerment, discussion of the broader cultural implications of that choice are elided. The campaigns suggest it is menstruation, rather than sexism, that holds women back today. This is significant, as these discourses aim to transform how contemporary women, and particularly young women, understand themselves as individuals benefitting from past feminist gains. The rhetoric of choice links their products to previous women's movements, giving menstrual suppression an implied authorization. This position was encapsulated by Candace Bushnell, Sex and the City creator and spokesperson for Seasonale, when she said: "When you think about what women have accomplished with 13 periods a year, [t]hink about what we can accomplish with only four. We have come a long way, but we've only just begun" (qtd. in Gettelman). When DTC campaigns cast menstruation as an individual choice, they artfully bring the topic of menstruation into public discourse without really talking about it, urging a seamless acceptance of the nonmenstruating body as a new norm for women. But this has long been the norm within institutions that cater to male bodies. ${ }^{19}$ Will the choice to menstruate become the truly radical choice of the future? In a world where menstrual suppression predominates, will it be an individual's fault if she opts to experience menstrual symptoms (and consequently must take bathroom breaks, take the day off of work, etc.)? I am apprehensive of any new "choice" that seems to replace one restrictive norm with another, punishing those who do not exercise that choice. Absent a frank discussion about what menstrual suppression means for women on a societal level, feminism may be repunctuated (interrupted or hindered) by these campaigns.

How, then, might we envision this issue in a way that repunctuates (accentuates or intensifies) a feminist concern for choice and the "emancipation of all subjects from unnecessarily constraining gender stereotypes" (Bruner 9)? This approach entails an acknowledgment that the relationship between menstruation and gendered identity remains unsettled. There is still a fruitful debate to be had about whether these pharmaceuticals are a valuable feminist technology, and it needs to be fleshed out outside of advertising discourses. We need a conversation about the value of menstruation that affirms women and considers menstrual suppression in the service of gender emancipation. ${ }^{20}$ Some may argue that menstruation continues to be an important serial connection between women, one worthy of celebration. ${ }^{21}$ How significant is the link created by menstruation-actual or assumed - to ongoing feminist movements? Others may argue that this serial connection is activated only if negative cultural attitudes about menstruation persist and suggest other connections around which feminist political subjectivity can be based. Today, there is an emerging third-wave feminist branch of "menstrual activism" that positively revalues menstruation through public campaigns, art, and poetry (Bobel; See also Chesler; McDonald). Gender diversity, including the recognition that not all who identify as women menstruate and not all who menstruate identify as women, is central to this movement (Bobel 159). It is possible to acknowledge that individuals have diverse relationships to menstruation and can make personal choices about whether to menstruate without constraining sexist stereotypes. 
This study has focused on discourses of menstrual suppression, but it also highlights a paradox important to understanding feminism and choice. As it continues to be deployed in new discursive terrains, rhetorical analysis is needed to identify moments when the rhetoric of choice purports to empower individuals with choices that may actually limit possibilities for others. Choices are not inherently good or bad, feminist or antifeminist. But any seemingly personal decision also entails a choice about whether to engage in a host of attendant concerns (sexism, classism, racism, heterosexism) within a wider web of collective relationships. ${ }^{22}$ To really value choice, then, is to look for rhetorical solutions that truly facilitate the exercise of choice for all.

Acknowledgments - The author thanks editor Valeria Fabj, Sonja K. Foss, the reviewers, Damien Smith Pfister, John Lyne, and Gordon Mitchell for their valuable feedback at various stages in this project's development.

\section{Notes}

1. In the context of abortion, for example, Celeste Michelle Condit explores "choice" as a ideograph in her Decoding Abortion Rhetoric (68-99). Catherine H. Palczewski develops a critique of "choice" in favor of "reproductive freedom" in her "Reproductive Freedom Transforming Discourses of Choice." Sara Hayden and D. Lynn O'Brien Hallstein's edited volume Contemplating Maternity in an Era of Choice demonstrates the breadth of reproductive issues now defined by rhetorics of choice.

2. Using birth control pills in this way is not new; the "off-label" practice of skipping the placebo or sugar pills in a packet has long been deployed to delay menstruation. However, this essay focuses on advertising campaigns that specifically market oral contraceptives for this purpose.

3. In the quest to understand whether there is anything worth saving about menstruation, it is important to avoid essentializing the experiences of individual women. Some view menstruation as a painful nuisance, some find it a source of empowerment, and still others just see it as a routine part of existence. The extent to which menstruation is actually meaningful to individuals, as Judith Butler reminds us, is varied. Even seemingly material biological differences between the sexes such as menstruation and pregnancy are always discursively and institutionally predefined by the policing of gender norms. In the same way that being biologically female does not guarantee the ability or the desire to become pregnant, menstruation is not universal (Butler qtd. in Osborne and Segal). Attitudes toward menstrual pain may be affected by many factors, including age, class, race, sexual preference, gender identity and expression, and cultural attitudes toward menstruation. These intersectional identities may impact an individual's attitudes toward menstrual pain in a variety of ways. For example, concern about menstrual pain could vary based on an individual's class status - if a woman cannot afford brand name pharmaceuticals, she may not have access to menstrual suppression. Alternately, an individual who does not intend to have biological children may see monthly menstrual pain as an unnecessary burden. The DTC advertisements studied in this essay tend to elide these differences in their attempts to attract their target consumers (i.e., mostly young women in heterosexual relationships).

4. For examples of medical and popular texts on the social history of menstruation see Buckley and Gottlieb; and van de Walle and Renne.

5. Though they attracted a flurry of interest when first introduced to the market, limited scholarly attention has been paid to the rhetorical dimensions of marketing menstrual suppression in pharmaceutical campaigns. For scholarly analyses of menstrual suppression to date, see Andrist; Johnston-Robledo, Barnack, and Wares; and Mamo and Fosket.

6. Duramed Pharmaceuticals is a subsidiary of Barr Laboratories. Teva Pharmaceutical Industries acquired both in 2008. Despite initial delays from the FDA, a fifth oral contraceptive, Wyeth's Lybrel (also known as Anya) was made available to consumers in 2008. Lybrel promised to stop menstruation altogether. Because Lybrel had the least-developed DTC campaign during the time period covered in this study (2006-2010), I have chosen not to feature it in my analysis. However, initial promotional materials for Lybrel made similar moves to the other DTC campaigns: They featured images 
of relaxed, happy, and healthy women. In one image, a White woman has her hands extended behind her. The wind is blowing through her hair, and her bare feet are slightly lifted off the ground, as if she does not have a care in the world and is ready to take flight. She appears in a green field with blue skies in the background (Lybrel). The decision to feature the woman in nature may have been intended to signal a move to recast the nonmenstruating body as a new normal, natural way of being.

7. M. Louise Ripley draws on argumentation models from Aristotle to Toulmin to van Eemeren and Grootendorst to make the case that advertisements function as arguments. Other studies, such as Davi Johnson (Thornton)'s analysis of the antidepressant Sarafem and Grow and colleagues' analysis of antidepressants, similarly make the case that DTC advertisements are valuable communication texts.

8. According to Dayna Porter, "Pharmaceutical industry spending on DTC promotion grew from $\$ 791$ million in 1999 to $\$ 4.8$ billion in 2006," in response to relaxed FDA regulations (51). As much as individuals like to think that they are immune to the persuasive power of advertising, the economic and power dynamics that animate the contemporary marketing landscape make them difficult to avoid (Schroeder 164). For specific survey data on the influence of DTC ads, see the FDA's report, "The Impact of Direct-to-Consumer Advertising" (U.S. Food and Drug Administration).

9. I studied each campaign's primary Web site: Yaz-us.com, Loestrin24.com, Seasonale.com, and Seasonique.com. These multimedia Web sites were ideal for studying DTC campaigns because they provided information about each pharmaceutical and included specific persuasive appeals aimed at consumers. Loestrin's Web site also hosted video clips from the campaign's television ads. I looked at secondary but related Web sites designed to create an audience for the drugs: wngti.com and UnderstandPMDD.com linked consumers to Yaz, while FewerPeriods.com provided information for those interested in limiting their periods to four times a year with Seasonale. Finally, I looked at a fourpage print advertisement that ran in Shape magazine in May 2007 because it promoted FewerPeriods. com (and thus was part of the larger Seasonale campaign). As I note, the heyday of DTC advertising of these oral contraceptives occurred between 2006 and 2010. Each Web site or related Web page analyzed is cited internally and in the works cited for this essay, which includes dates accessed. This is important because the campaigns were revised over time. The original campaigns analyzed can be viewed using Internet Archive's Wayback Machine (http://www.archive.org). At the time of press, these oral contraceptives are still on the market, but their campaigns have been abandoned or scaled back considerably.

10. Rhetorical interventions into biomedicine include studies with implications for women patients, such as the B-06 lumpectomy controversy (Keränen), the marketing of female sexual dysfunction (Segal, "'Female Sexual Dysfunction'”), and social contexts for gendered talk about depression (Emmons; Hurt).

11. A gulf often exists between the abstract possibility and the material conditions necessary to be able to actually exercise choice. This disparity has long been acknowledged when discourses of reproductive freedom bump up against discourses of reproductive justice. For example, the widespread availability and relative reliability of the birth control pill allows some women (those who have access to health care and can afford prescriptions) to seize control of their own reproductive futures, yet it has also enabled an unsavory history of medical experimentation, in which women of color, economically underprivileged women, and women with disabilities have been targets of forced population control (Smith 131-32). See also Price, Rapp, and Mitchell and Happe on the role of race, gender, and class and informed consent in genetics.

12. Menstrual pain can take a variety of forms but may include headaches, migraines, bloating, upset stomach, cramping, and pain and pressure in the abdomen, lower back, thighs, and hips. Although highly contested, PMS and PMDD are related women's health conditions that can also result in physical, emotional, and psychological pain. Some argue that the treatment of PMS and PMDD is important for women to live less painful lives, while others believe that PMS and PMDD are labels used to medicalize women's bodies (Ussher 84). For example, Jane Ussher sees PMS as a rhetorical accomplishment that "is constructed through women's narratives, and through the public and private discourse produced by experts" (39).

13. On this point, Susan J. Douglas's concept of "enlightened sexism" is illuminating. She makes sense of the ideological generation gap by suggesting that media-driven images of women in power have created false postfeminist fantasies that indicate that feminism's work is done. 
14. This "unbranded educational campaign" provided links so that savvy consumers could trace each element of the campaign back to Bayer Healthcare Pharmaceuticals, providing a level of transparency that is not always apparent in viral marketing efforts.

15. Both wngti.com and UnderstandPMDD.com are currently offline. The original Web sites can be viewed on the Internet Archive's Wayback Machine (http:// www.archive.org).

16. The Loestrin campaign launched with an emphasis on shortening menstrual periods, with Cammie as the major figure in the online and television advertisements. Since 2008, the campaign has been updated, excising Cammie and boasting a new slogan: "Short, light ... right."

17. Like Yaz, early Seasonale television advertisements received FDA warnings for minimizing safety risks associated with the drug (see Chitale).

18. However, the Website concedes one drawback upfront: "While you get the convenience of 4 periods a year, you are also more likely to have spotting and breakthrough bleeding (which varies from slight spotting to a flow much like a regular period) than with a traditional monthly birth control pill. This is common and should decrease over time. During the first year, total bleeding days are similar to a traditional birth control Pill" (Seasonale.com).

19. It is worth questioning whether parallel arguments are already in circulation for women who choose to embrace other identifiable links between women, such as the ability to bear children, or individuals who choose not to take hormonal birth control. For more on the institutional nonacceptance of menstruation, see Young's "Menstrual Meditations" in On Female Body Experience, pp. 113-17.

20. An instructive example is the Boston Women's Health Book Collective's Our Bodies, Ourselves, which treats menstrual suppression, like many scientific controversies, as an issue that is still open for debate. The reason for this is twofold: lack of scientific information on the long-term impacts of menstrual suppression and cultural reservations (e.g., "How can we make informed choices about menstruation in a culture that tells us that we are dirty when we bleed?"; 255). Marianne MacPherson, the primary editor of the "Sexual Anatomy, Reproduction, and Menstruation" chapter in Our Bodies, Ourselves notes that she chose not to discuss specific companies or products because it might "obscure the larger debate around the safety and desirability of menstrual suppression in general" (194).

21. There are a number of texts - some fantastical, some not - that explicitly value menstruation, including Dena Taylor's Red Flower; Gloria Steinem's "If Men Could Menstruate" in her Outrageous Acts and Everyday Rebellions); and Gerd Brantenberg's Egalia's Daughters, which includes the Grand Menstruation Games (249-55).

22. This is akin to what Catriona Mackenzie and Natalie Stoljar call "relational autonomy" or the "implications of the intersubjective and social dimensions of selfhood and identity for conceptions of individual autonomy and moral and political agency" (4).

\section{Works Cited}

Abrams, Thomas. Letter to Reinhard Franzen, Oct. 3, 2008. Accessed online June 13, 2010: http:// www.fda.gov/downloads/Drugs/GuidanceComplianceRegulatoryInformation/EnforcementActivitiesbyFDA/WarningLettersandNoticeofViolationLetterstoPharmaceuticalCompanies/ ucm053993.pdf

Andrist, Linda C. “The Implications of Objectification Theory for Women's Health: Menstrual Suppression and 'Maternal Request' Cesarean Delivery." Health Care for Women International 29 (2008): 551-65.

Baumgardner, Jennifer, and Amy Richards. "The Number One Question About Feminism." Feminist Studies 29.2 (2003): 448-52.

BBC News. “Girl Power Goes Mainstream.” BBC News UK, Jan. 17, 2002. Accessed online Feb. 22, 2013: http://news.bbc.co.uk/2/hi/uk_news/1765706.stm

Bobel, Chris. New Blood: Third-Wave Feminism and the Politics of Menstruation. New Brunswick: Rutgers UP, 2010. 
Boston Women's Health Book Collective. Our Bodies, Ourselves: A New Edition for a New Era. New York: Simon and Schuster, 2005.

Brantenberg, Gerd. Egalia's Daughters: A Satire of the Sexes. Seattle: Seal, 1985.

Braun, Virginia. "'The Women Are Doing It for Themselves': The Rhetoric of Choice and Agency Around Female Genital ‘Cosmetic Surgery.' " Australian Feminist Studies 24:60 (2009), 233-49.

Bruner, M. Lane. "Producing Identities: Gender Problematization and Feminist Argumentation." Argumentation and Advocacy 32:4 (1996), 185-200.

Buckley, Thomas, and Alma Gottlieb, eds. Blood Magic: The Anthropology of Menstruation. Berkeley: Univ. of California Press, 1998.

Charland, Maurice. "Politics: Constitutive Rhetoric." Encyclopedia of Rhetoric, ed. Thomas Sloane. New York: Oxford UP, 2001. 616-19.

Chesler, Giovanna, dir. Period: The End of Menstruation. The Cinema Guild, 2006. Film.

Chitale, Kay A. “Letter to Joseph Carrado." Dec. 24, 2004. Accessed online June 20, 2013: http:// www.fda.gov/downloads/Drugs/GuidanceComplianceRegulatoryInformation/EnfEnforcementActivitiesby/WarningLettersandNoticeofViolationLetterstoPharmaceuticalWarningLe/ ucm054665.pdf

Condit, Celeste Michelle. Decoding Abortion Rhetoric: Communicating Social Change. Urbana: U of Illinois Press, 1990.

Delaney, Janice, Mary Jane Lupton, and Emily Toth. The Curse: A Cultural History of Menstruation. Urbana: U of Illinois Press, 1988.

Douglas, Susan J. Enlightened Sexism: The Seductive Message That Feminism's Work Is Done. New York: Times Books, 2010.

Duramed Pharmaceuticals. Advertisement. Shape (May 2007): btwn 48-50.

Edelman, Alison. "Menstrual Nirvana: Amenorrhea through the Use of Continuous Contraceptives." Current Women's Health Reports 2.6 (2002): 434-38.

Ehrenreich, Barbara, and Deidre English. Complaints and Disorders: The Sexual Politics of Sickness. New York: Feminist Press at the City U of New York, 1973.

Elliott, Carl. Better Than Well: American Medicine Meets the American Dream. New York: Norton, 2003.

Emmons, Kimberly. "'All on the List': Uptake in Talk About Depression." Rhetoric of Healthcare: Essays Toward a New Disciplinary Inquiry, ed. Barbara Heifferon and Stuart C. Brown. Cresshill, NJ: Hampton, 2008. 159-80.

Ferguson, Michaele L. "Choice Feminism and the Fear of Politics." Perspectives on Politics 8.01 (2010): 247-53.

FewerPeriods.com. “Fewer Periods.” Duramed Pharmaceuticals. 2006. Accessed online March 13, 2008.

Fixmer-Oraiz, Natalie. “No Exception Postprevention: 'Differential Biopolitics' on the Morning After." Contemplating Maternity in an Era of Choice: Explorations into Discourses of Reproduction, ed. Sara Hayden and D. Lynn O’Brien Hallstein. Lanham, MD: Lexington Books, 2010. 27-48.

Foss, Sonja K. Rhetorical Criticism: Exploration and Practice., 4th ed. Long Grove, IL: Waveland P, 2009.

Fried, Jennifer. “Off the Rag." Salon.com. Nov. 25, 2003. Accessed online Nov. 27, 2006: http://dir. salon.com/story/mwt/feature/2003/11/25/periods/index.html

Gettelman, Elizabeth. "That Time of the ... Year." Washington Post, June 8, 2004. Accessed online June 20, 2013: http://www.washingtonpost.com/wp-dyn/articles/A23277-2004Jun7.html

Grosz, Elizabeth. Volatile Bodies: Towards a Corporeal Feminism. Bloomington: Indiana Univ Press, 1994. 
Grow, Jean, Jin Seong Park, and Xiaoqi Han. "Your Life Is Waiting!: Symbolic Meanings in Directto-Consumer Antidepressant Advertising." Journal of Communication Inquiry 30.2 (2006): 163-88.

Hains, Rebecca C. "Power Feminism, Mediated: Girl Power and the Commercial Politics of Change." Women's Studies in Communication 32:1 (2009): 89-113.

Haruch, Steve. "Easy, Breezy 'Feminism', \& the Problem with The Veronicas." Nashrille Scene, May 7, 2009. Accessed online June 13, 2010: http://www.nashvillescene.com/nashville/ easy-breezy-feminism-and-the-problem-with-the-veronicas / Content?oid=1200976

Hayden, Sara. "Reclaiming Bodies of Knowledge: An Exploration of the Relationship Between Feminist Theorizing and Feminine Style in the Rhetoric of the Boston Women's Health Book Collective." Western Journal of Communication 61.2 (1997): 127-63.

Hayden, Sara and D. Lynn O'Brien Hallstein, eds. Contemplating Maternity in an Era of Choice: Explorations into Discourses of Reproduction. Lanham, MD: Lexington Books, 2010.

Hurt, Nicole E. "Disciplining through Depression: An Analysis of Contemporary Discourse on Women and Depression." Women's Studies in Communication 30.3 (2007): 284-309.

Johnson, Davi. "Selling Sarafem: Priestly and Bardic Discourses in the Construction of Premenstrual Syndrome." Women's Studies in Communication 27.3 (2004): 330-51.

Johnston-Robledo, Ingrid, Jessica Barnack, and Stephanie Wares. “'Kiss your Period Good-bye': Menstrual Suppression in the Popular Press." Sex Roles 54 (2006): 353-60. ,

Jordan, John W. "The Rhetorical Limits of the Plastic Body." Quarterly Journal of Speech 90 (2004): 327-58.

Keränen, Lisa. "Mapping Misconduct: Demarcating Legitimate Science from 'Fraud' in the B-06 Lumpectomy Controversy." Argumentation and Advocacy 42.2 (2005): 94-113.

Loestrin24.com. "Cammie's Story." Warner Chilcott, 2008. Accessed online Oct. 26, 2008. http:// www.loestrin24.com/tv.php\#top

- . "Loestrin 24fe." Warner Chilcott. 2008. Accessed online Mar. 13, 2008.

Lorber, Judith, and Lisa Jean Moore. Gendered Bodies: Feminist Perspectives. New York: Oxford UP, 2011.

Lybrel: Discover More About a Highly Effective Option in Birth Control. Philadelphia: Wyeth Pharmaceuticals, 2007. Pamphlet.

Lyne, John. "Contours of Intervention: How Rhetoric Matters to Biomedicine." Journal of the Medical Humanities 22.1 (2001): 3-13.

Lyne, John, and Carolyn R. Miller. "Rhetoric Across the Disciplines: Rhetoric, Disciplinary, and Fields of Knowledge." The Sage Handbook of Rhetorical Studies, eds. Andrea A. Lunsford, Kirt H. Wilson, and Rosa A. Eberly. Thousand Oaks, CA: Sage, 2009. 167-74.

Mackenzie, Catriona, and Natalie Stoljar. "Introduction: Autonomy Refigured." Relational Autonomy: Feminist Perspectives on Autonomy, Agency, and the Social Self, ed. Catriona Mackenzie and Natalie Stoljar. Oxford: Oxford UP, 2000. 3-34.

MacPherson, Marianne. "Breasts, Blood, and the Royal V: Challenge in Revising Anatomy and Periods for the 2005 Edition of Our Bodies, Ourselves." NWSA Journal 17.1 (2005): 190-96.

Mamo, Laura, and Jennifer Fosket. "Scripting the Body: Pharmaceuticals and the (Re)making of Menstruation." Signs: Journal of Women in Culture and Society 34 (2009): 925-49.

Mandziuk, Roseann M. “'Ending Women's Greatest Hygienic Mistake': Modernity and Mortification of Menstruation in Kotex Advertising, 1921-1926." WSQ: Women's Studies Quarterly 38.3/4 (2010): 42-62.

McCarver, Virginia. “The Rhetoric of Choice and 21st-Century Feminism: Online Conversations about Work, Family, and Sarah Palin." Women's Studies in Communication 34 (2011): 24-41. 
McDonald, Shauna M. "Leaky Performances: The Transformative Potential of Menstrual Leaks." Women's Studies in Communication 30.3 (2007): 340-57.

McRobbie, Angela. "Post-Feminism and Popular Culture." Feminist Media Studies 4.3 (2004): 255-64.

MediaEdge: Cia. "Bayer (Yaz)." 2010. Accessed online June 13, 2010: http://www.mecglobal.com/ our-work/case-studies/bayer-yaz/

Mitchell, Gordon R., \& Kelly Happe. "Informed Consent After the Human Genome Project." Rhetoric and Public Affairs 4.3 (2001): 375-406.

O’Brien Hallstein, D. Lynn. "Public Choices, Private Control: How Mediated Mom Labels Work Rhetorically to Dismantle the Politics of Choice and White Second Wave Feminist Successes." Contemplating Maternity in an Era of Choice: Explorations into Discourses of Reproduction, ed. Sara Hayden and D. Lynn O’Brien Hallstein. Lanham, MD: Lexington, 2010. 5-26.

Osborne, Peter, and Lynne Segal. “Gender as Performance: An Interview with Judith Butler." Radical Philosophy 67 (1994): 32-39.

Palczewski, Catherine H. "Reproductive Freedom: Transforming Discourses of Choice." Contemplating Maternity in an Era of Choice: Explorations into Discourses of Reproduction, ed. Sara Hayden and D. Lynn O'Brien Hallstein. Lanham, MD: Lexington, 2010. 73-94.

Payne, January W. "Period: Full Stop?" Washington Post. June 6, 2006. Accessed online Dec. 11, 2006: http://www.washingtonpost.com/wp-dyn/content/article/2006/06/05/ AR2006060500845.html

Porter, Dayna M. “Direct-to-Consumer (DTC) Pharmaceutical Marketing: Impacts and Policy Implications." SPNHA Review 7.1 (2011): 51-70.

Powell-Dunford, Nicole, Amanda S. Cuda, Jeffrey L. Moore, Mark S. Crago, and Patricia A. Deuster. "Menstrual Suppression Using Oral Contraceptives: Survey of Deployed Female Aviation Personnel." Aviation, Space, and Environmental Medicine 80.11 (2009): 971-75.

Price, Kimala. "What Is Reproductive Justice? How Women of Color Activists Are Redefining the Pro-Choice Paradigm." Meridians 10.2 (2010): 42-65.

Rapp, Rayna. "Refusing Prenatal Diagnosis: The Meanings of Bioscience in a Multicultural World." Science, Technology, and Human Values 23.1 (1998): 45-70. ,

Ripley, M. Louise. "Argumentation Theorists Argue that an Ad Is an Argument." Argumentation 22.4 (2008): 507-19.

Schroeder, Jonathan E. Visual Consumption. London: Routledge, 2002.

Seasonale.com. "Seasonale: Birth Control That's the Same But Different." Duramed Pharmaceuticals. 2008. Accessed online Mar. 13, 2008. http://www.seasonale.com/home.aspx

_. "Seasonale Personal Planner." Duramed Pharmaceuticals. 2008. Accessed online Mar. 13, 2008: http://www.seasonale.com/IsSeasonaleForYou/PersonalPlanner.aspx

Seasonique.com. Duramed Pharmaceuticals. 2009. Web. 11 Jul. 2010.

—. "The Real Story of the Pill." 2009. Accessed online July 11, 2010: https://www.seasonique.com/about/the-real-story-of-the-pill

Segal, Judy Z. "'Female Sexual Dysfunction' and a Rhetoric of Values." Rhetoric of Healthcare: Essays Toward a New Disciplinary Inquiry, ed. Barbara Heifferon and Stuart C. Brown. Cresshill, NJ: Hampton, 2008. 33-50.

- . "Rhetoric of Health and Medicine." The Sage Handbook of Rhetorical Studies, ed. Andrea A. Lunsford, Kirt H. Wilson, and Rosa A. Eberly. Thousand Oaks, CA: Sage, 2009. 227-45.

Shugart, Helene A., Catherine Eggley Waggoner, and D. Lynn O’Brien Hallstein. "Mediating Third Wave Feminism: Appropriation as Postmodern Media Practice." Critical Studies in Media Communication 18.2 (2001): 194-210. ," 
Smith, Andrea. "Beyond Pro-Choice Versus Pro-Life: Women of Color and Reproductive Justice." NWSA Journal 17.1 (2005): 119-40.

Snyder-Hall, R. Claire. "Third Wave Feminism and the Defense of 'Choice.'” Perspectives on Politics 8.1 (2010): 255-61. ,

Steinem, Gloria. Outrageous Acts and Everyday Rebellions. New York: Holt, 1995.

Taylor, Dena. Red Flower: Rethinking Menstruation. Freedom, CA: Crossing, 1988.

Trego, Lori L. “Military Women's Menstrual Experiences and Interest in Menstrual Suppression During Deployment." Journal of Obstetric, Gynecologic, and Neonatal Nursing 36.4 (2007): 342-47.

U.S. Food and Drug Administration. "The Impact of Direct-to-Consumer Advertising." FDA, 2011. Accessed online Feb. 23, 2013: http://www.fda.gov/Drugs/ResourcesForYou/Consumers/ ucm143562.htm

Ussher, Jane M. Managing the Monstrous Feminine: Regulating the Reproductive Body. London: Routledge, 2006.

van de Walle, Etienne, and Elisha P. Renne, eds. Regulating Menstruation: Beliefs, Practices, Interpretations. Chicago: U of Chicago P, 2001.

Walker, Whitney. “Why I Fight Back." Listen Up! Voices from the New Feminist Generation. Ed. Barbara Findlen. New York: Seal, 2001. 126-32.

Willard, Barbara E. "Feminist Interventions in Biomedical Discourse: An Analysis of the Rhetoric of Integrative Medicine." Women's Studies in Communication 28.1 (2005): 115-48.

Wngti.com. 2008. Accessed online July 11, 2010. http:// web.archive.org/web/20080430214952/ http://wngti.com

Yaz-us.com. 2006. Accessed online Mar. 13, 2008.

Young, Iris Marion. On Female Body Experience: Throwing Like a Girl and Other Essays. Oxford: Oxford UP, 2005.

- Intersecting Voices: Dilemmas of Gender, Political Philosophy, and Policy. Princeton, NJ: Princeton UP, 1997.

Zita, Jacquelyn N. Body Talk: Philosophical Reflections on Sex and Gender. New York: Columbia UP, 1998. 